\title{
Investing in energy conversion technologies - an optimum vintage portfolio selection approach
}

Citation for published version (APA):

van Zon, A. H., \& Fuss, S. (2005). Investing in energy conversion technologies - an optimum vintage portfolio selection approach. UNU-MERIT, Maastricht Economic and Social Research and Training Centre on Innovation and Technology. MERIT-Infonomics Research Memorandum Series No. 013 https://doi.org/10.26481/umamer.2005013

Document status and date:

Published: 01/01/2005

DOI:

10.26481/umamer.2005013

Document Version:

Publisher's PDF, also known as Version of record

\section{Please check the document version of this publication:}

- A submitted manuscript is the version of the article upon submission and before peer-review. There can be important differences between the submitted version and the official published version of record.

People interested in the research are advised to contact the author for the final version of the publication, or visit the DOI to the publisher's website.

- The final author version and the galley proof are versions of the publication after peer review.

- The final published version features the final layout of the paper including the volume, issue and page numbers.

Link to publication

\footnotetext{
General rights rights.

- You may freely distribute the URL identifying the publication in the public portal. please follow below link for the End User Agreement:

www.umlib.nl/taverne-license

Take down policy

If you believe that this document breaches copyright please contact us at:

repository@maastrichtuniversity.nl

providing details and we will investigate your claim.
}

Copyright and moral rights for the publications made accessible in the public portal are retained by the authors and/or other copyright owners and it is a condition of accessing publications that users recognise and abide by the legal requirements associated with these

- Users may download and print one copy of any publication from the public portal for the purpose of private study or research.

- You may not further distribute the material or use it for any profit-making activity or commercial gain

If the publication is distributed under the terms of Article $25 \mathrm{fa}$ of the Dutch Copyright Act, indicated by the "Taverne" license above, 


\section{MERIT-Infonomics Research Memorandum series}

Investing in Energy Conversion Technologies

- An Optimum Vintage Portfolio Selection Approach -

\section{Adriaan van Zon \& Sabine Fuss}

\section{5-013}

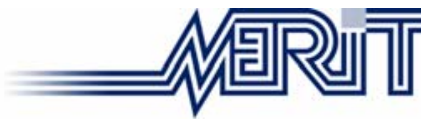

MERIT - Maastricht Economic Research Institute on Innovation and Technology

PO Box 616

6200 MD Maastricht

The Netherlands

$\mathrm{T}:+31433883875$

F: +31433884905

http://www.merit.unimaas.nl e-mail:secr-merit@merit.unimaas.nl

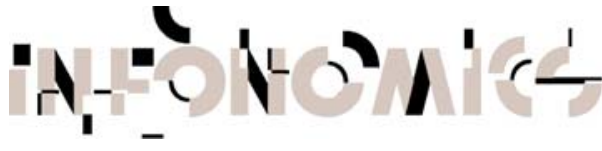

International Institute of Infonomics

c/o Maastricht University PO Box 616

6200 MD Maastricht

The Netherlands

T: +31433883875

F: +31 453884905

http://www.infonomics.nl e-mail: secr@infonomics.nl 


\title{
Investing in Energy Conversion Technologies - An Optimum Vintage Portfolio Selection Approach -
}

\author{
Adriaan van Zon and Sabine F uss \\ MERIT, Maastricht University - J une 2005
}

\begin{abstract}
The methods by which fuels can be converted into el ectricity all belong to different "technology families": the "gas-fired-turbine-family", the "coal-fired-turbinefamily", etc. E ach family consists of different generations of similar technologies, as in a vintage model. Within a family, the latest generation embodies the most recent level and type of knowledge, becoming more and more outdated as new generations arrive Producers face the problem how to compose their portfolio of families to minimize risk-adjusted costs of investment and production under a given demand constraint. Risk emanates from a number of uncertainties, such as volatile fuel prices and uncertain (prospects of) technological change. The paper presents a model capturing these features by integrating elements from financial Optimum Portfolio Theory (OPT) in a vintage capital investment framework. We find that the cumulative nature of embodied technical change gives rise to investment responses to (changes in) uncertainty that are in between the 'standard' results of OPT and Real Option Theory.
\end{abstract}




\section{Introduction}

There are several ways, in which el ectricity can be produced. One can use carbon-based fuels like oil, coal or natural gas to drive a generator in order to obtain electricity. Alternatively, nuclear power plants, wind- or hydrogen-based plants can be used. Each of these conversion possibilities belongs to its own "family" of conversion technologies. We have the "gas-fired-turbine-family", the "coal-fired-turbine-family" and so on. Each technology family in turn consists of different generations of similar technologies, as in a vintage model of production ${ }^{1}$. Within a family, each generation embodies the level and type of knowledge that was cutting edge at the time the generation came into existence. And each generation that was new at the time of its arrival, will become obsolete or at least (partly) outdated, as soon as a new generation arrives.

The reason why we are emphasising this structure within a technology family is that technical change does not fall like "manna from heaven" (Robinson, 1962). Instead, it needs to be bought and paid for in the form of new machines and equipment. This is because in el ectricity production the most important type of technical change is of the embodied kind that comes in the form of quality improvements (or more fundamental variations) of existing machinery and equipment designed to perform certain productive tasks. As fuel efficiency and load factors usually do not change ex post for a given vintage, we will disregard disembodied technological improvements ex post, and focus only on the effects of the embodiment of technical change? ${ }^{2}$. This has of course been the subject of the vintage literature ever since vintage model ling has been conceived of. The novelty of this paper is the way in which uncertainty surrounding the rate of embodied technical change will have an impact on investment behaviour.

Furthermore, we would like to stress the fact that there are different technology families in use in electricity production by one and the same firm at

\footnotetext{
1 See Gregory and J ames (1973) for further arguments why vintage modeling is appropriate for the electricity sector, such as the substantial initial investment outlays required to start electricity production (Gregory and J ames, 1973, p. 1134).

2 M ore specifically, this can be technical change, which leads to improved fuel efficiency, i.e. less input for the same amount of output, or increased capital productivity, i.e. less capacity would have to be installed to produce the same amount of electricity.
} 
the same point in time. These days, electricity providers do not rely on a single technology family, but carefully compose a portfolio of different generating techniques. Apparently, the various electricity production families are thus imperfect substitutes for each other. Otherwise, the most efficient family would drive out all the other ones. The question then arises why these families are used contemporaneously and more or less continuously. There are several reasons for this. Some families perform the best under more or less constant production circumstances. Their output levels can only be changed at relatively high cost, which causes significant problems if forecasts do not match actual demand. Other families can be used to meet peaks in demand because their output levels can be easily adjusted to unexpected fluctuations in demand. Gas turbines, for example, have high generation costs, but require only low instalment expenses, while coalbased technologies have much higher capital costs, but lower generation costs. Therefore, gas is usually used for peak loads and coal for base loads. Other reasons are that prices of fuels can be quite volatile, which is especially evident in the case of oil, for instance.

Consequently, the return to electricity production depends on price movements and the corresponding composition of the el ectricity capital stock the latter in terms of technology families. After all, these families determine the fuel type and the way, in which the corresponding capital goods can be used in electricity production (e.g. peak-load versus base-load). However, the profitability of electricity production also depends on the size-distribution of generations within families since that determines the efficiency of the family in meeting its production goals. Summing up, the volatility of the costs of electricity production depends very much on the technology family composition of the capital stock of the electricity sector as well as on the size-distribution of generations within families.

Next to the uncertainty emanating from volatile fuel prices, electricity producers face risks with respect to technology. Ex ante, it is not perfectly clear how capital and fuel productivity will evolve over time. A higher variance in the growth rates of these productivities will make the corresponding technology family less attractive than their more secure counterparts, if electricity producers 
are risk-averse. We therefore expect optimising but risk-averse producers to decrease the portfolio-investment-share of technology families that are characterised by a relatively high technological uncertainty.

A part from cost fluctuations through price- and technological uncertainty, there is also demand uncertainty to take into consideration. The latter can be covered by finding an investment program that optimises some objective function that is defined over a set of demand scenarios, each occurring with their own subjective probability. Because we want to have as clear an impression as possible of the effects of technological and price uncertainty in an OPT setting, we leave out as many distracting details as possible, among which these different demand scenarios. ${ }^{3}$ Thus, we focus only on price and technological uncertainty as the most important determinants of the cost volatility in the electricity sector and therefore also the volatility of returns to investment.

The problem of volatile returns to investment and how to counter this through the adjustment of the underlying "stocks" is covered extensively in Optimum Portfolio Theory (further called OPT), which deals with the optimum composition of financial investment portfolios in terms of its individual financial assets (Markowitz, 1952, 1991). Awerbuch and Berger (2003) apply meanvariance portfolio optimisation techniques in the style of Markowitz (1952) to the energy market of the European Union. Their results indicate that the existing portfolio of EU power generating technologies is sub-optimal and therefore nonefficient, i.e. there are portfolios combining lower risks with higher returns. Our paper differs from Awerbuch and Berger (2003) insofar that we have a different definition of technological uncertainty and our results do not al ways comply with their findings either. They find that fuel price risk al ways dominates the other types of risks that they examine, while in our model the results for fuel price risk reductions are qualitatively and significantly different from those under less technological uncertainty. Another contribution to the problem of electricity planning is by Madlener, Kumbaroglu and Ediger (2005). In their model uncertainty pertains to fluctuations in demand, peak load capacity, generation

\footnotetext{
3 In a preliminary version of the model we had implemented such scenarios and also the distinction between peak- and base-load technologies. But apart from making the model less transparent, these aspects do not add anything particularly interesting to the portfolio set-up.
} 
costs and the price of el ectricity. In particular, they model the expected value of these items as discrete stochastic autoregressive moving average processes of orders $p$ and $q$, ARMA $(p, q)$. They use a dynamic programming approach, but their approach to maximize the net present value of optimal vintages is otherwise similar to our set-up including their constraints with respect to demand and capacity. Their results are based on data for the Turkish el ectricity sector, where more and more gas has been installed over the last years. However, the model predicts that coal should be a lot more dominant because coal prices are a lot less volatile than gas prices in Turkey. We will see later on that this is in principle in line with our findings, although we should stress here that the results we find depend a lot on the weight that is attached to uncertainty (degree of risk aversion) in the objective function.

The set-up of the rest of the paper is as follows. In section 2 we provide a brief outline of the model. We describe the vintage structure and the way in which the variances of expected fuel and capital costs and productivity growth are incorporated in this vintage context. Section 3 is devoted to a number of model simulations in which we change the degree of uncertainty about fuel prices and technological uncertainty. Section 4 contains a summary and some concluding remarks.

\section{The Model}

\subsection{Framework}

The investment decision framework essentially uses a two-dimensional clay-clay vintage model. The first dimension is the technology family dimension mentioned in the introduction, while the second dimension is the usual (technological) quality dimension, proxied by the time of installation of a particular vintage. The technology families, as stated before, are characterised by the fact that they use a certain fuel. Different vintages belonging to such a family then embody the different states of the technology at the moment they were installed. 
The simultaneous use of technologies mimics the fact that in electricity production various technol ogies are used next to each other, because they are imperfect substitutes for each other on a number of accounts that have al ready been discussed in the introduction. For instance, while one technology family may be relatively cheap to use for base-load energy production, other technologies can be used for peak load production but at relatively high costs. In addition, some technologies may have limited scope for productivity growth, but that productivity growth itself may be relatively certain to occur, while other technologies may seem to be highly promising in terms of productivity growth, but also fairly risky in terms of the actual achievement of these promises. This suggests that from a longer term perspective, and thus facing uncertain perspectives of future development of these technologies, Optimum (financial) Portfolio Theory may actually provide a suitable modelling framework for describing investment behaviour in the electricity sector. Since in this case we are dealing with physical capital investment rather than financial capital investment, we will need to take into account that a physical capital portfolio can change only relatively gradually through investment at the margin of the capital stock, i.e. investment in new vintages of machinery and equipment that embody the latest versions of a specific technology. Due to the ex post sunk cost character of physical investment, we should take an intertemporal perspective rather than the myopic perspective that one can adopt in case of financial portfolio theory without any (significant) adjustment costs. We do this by developing a simultaneous investment plan for different technology families over a planning period of a given length using the (expected) user cost of capital, rather than the present value of a piece of equipment at the moment it is bought.

There are three types of costs to take into consideration per technology family. The first is fixed costs, which depend on the amount of installed capacity. The second type is variable fuel costs based on the capacity actually used. The third type is quasi-rents forgone due to capacity shortages that might occur due to unexpected peaks in demand, but for reasons of transparency, we disregard the latter cost item. ${ }^{4}$ But even though we disregard unexpected fluctuations in

\footnotetext{
4 As stated before, we disregard demand fluctuations here, but when we introduced different
} 
demand in this paper, it should be noted that such fluctuations can easily be integrated in our model-setting where producers are interested in installing capacity that minimises the expected variance adjusted cost of buying and operating that capacity under different demand scenarios, each having their own probability of being realised. For a given investment plan, the different scenarios will give rise to equally different scenario costs and variances of these costs. It is but a relatively small step then, to (re)define the investment decision problem in terms of the scenario-weighted (and scenario-variance adjusted) expected costs of building and operating production capacity.

In the remainder of this section, we first explain how the vintage model works, and then describe how price and technological variance influence investment decisions.

\subsection{The vintage model}

The technology families referred to above, are characterised by the fact that they use a certain fuel as well as a certain basic conversion technology turning this fuel into electricity. Different vintages belonging to such a family then embody the different states of the basic conversion technology at the moment they were installed. In the description of the model, we will be using the index $f$ to denote a technology family (or fuel type), an index $v$ to denote a vintage, and $\mathrm{t}$ to denote time. The variables ? $\mathrm{K}^{\mathrm{f}}, \mathrm{PY}^{\mathrm{f}}, \mathrm{PX}^{\mathrm{f}}$ and $? \mathrm{~F}^{\mathrm{f}}$ are the (vintage) level of investment, capacity output, actual output and fuel consumption per technology, respectively. We allow for embodied capital and fuel saving technical change at a proportional rate with a given expected value and a given (expected) variance of that rate.

The vintage part of the model can now be summarised as follows. For the development over time of the amount of capital associated with each vintage, we have: 
$\Delta K_{v, t}^{f}=e^{\left.-\delta^{f} \cdot(t-v)\right)} \cdot \Delta K_{v, v}^{f}$

where $\Delta K_{v, t}^{f}$ measures the amount of capital still left at time t of a vintage that was installed at time v. In equation (1), $\delta^{f}$ is the (constant) exponential rate of physical decay. Hence equation (1) states that the amount of capital associated with a vintage installed at time $\mathrm{v}$ will fall at a rate of $\delta^{f}$ percent per year due to technical wear and tear. F or capacity output associated with a vintage $v$ we have:

$\Delta Y_{v, t}^{f}=\Delta K_{v, t}^{f} / \kappa_{v}^{f}$

In equation (2) $\kappa_{v}^{f}$ is the capital-output ratio associated with vintage $v$ at time $t$. As we assume that there is no ex post disembodied technical change, $\kappa_{v}^{f}$ does only depend on v. However, embodied (capital and fuel saving) technical change takes place at a given expected proportional rate and with a given variance. We therefore have:

$\kappa_{v}^{f}=\kappa_{0}^{f} \cdot e^{\hat{\kappa}^{f} \cdot v}$

By analogy, we postulate for the fuel-output ratio $\varphi_{v}^{f}$ that:

$\varphi_{v}^{f}=\varphi_{0}^{f} \cdot e^{\hat{\varphi}^{f} \cdot v}$

Hence, for fuel consumption per vintage we find:

$\Delta F_{v, t}^{f}=\varphi_{v}^{f} \cdot \Delta X_{v, t}^{f}$

We can use (2) to find the 'demand' for capital per vintage in function of the level of installed capacity: 
$\Delta K_{v, t}^{f}=\kappa_{v}^{f} \cdot \Delta Y_{v, t}^{f}$

\subsection{Incorporating irreversible ex ante investment dedisions under uncertainty}

Given the factor requirement constraints explained above, there are now two different problems to solve. The first concerns the question how much to invest in each technology family, given the specific characteristics of these families in terms of capital and fuel costs, but also with respect to their technological prospects, volatility of fuel price developments and so on. The second problem is the timing of investment. Since investment is irreversible ex post (i.e. capital costs are sunk), the investment planning process should involve both forward looking expectations as well as a measure of risk aversion in order to accommodate this irreversibility. To this end, we have to specify how costs (both fixed and variable) are expected to evolve over time and how the associated variances evolve over time, but also how the overall variance of the technology family portfolio can be integrated in the investment decision. We do this by assuming that risk-averse electricity producers will want to maximise the weighted sum of the expected present value of total cost and the variance of that cost by carefully composing their vintage portfolio in both the family dimension and the 'quality'-dimension (where later vintages obviously rank higher in quality), because as rational, risk-averse investors they are expected to diversify risk by spreading their investments both over technology families and over time.

In order to calculate the technology family portfolio variance of the present value of buying and using the vintage portfolio, we first describe how capital and fuel costs are expected to evolve over time, and what the corresponding variance of these expectations will be.

\subsection{Expected variance in fixed and variable cost components}

The present value (PV) of capital and fuel costs for all technology families $f$ over a planning period with length $\theta$ is given by: 


$$
P V=\sum_{f} \sum_{t=1}^{\theta} e^{-\rho t} \cdot \sum_{v=1}^{t}\left(P_{v}^{f} \cdot\left(r_{v}+\delta\right) \cdot \kappa_{v}^{f} \cdot Y_{v}^{f} \cdot e^{-\delta \cdot(t-v)}+Q_{t}^{f} \cdot \varphi_{v}^{f} \cdot X_{v, t}^{f}\right)
$$

In equation (5), $\rho$ is the rate of discount, while $r_{v}$ is the interest rate at the time vintage $\mathrm{v}$ is installed. $P_{v}^{f}$ is the cost of a unit of investment of vintage $\mathrm{v}$ at the time of its installation. Equation (5) shows that depreciation charges are valued at historic cost-prices, rather than at replacement value. ${ }^{5} \kappa_{v}^{f}$ is the capital- (capacity-) output ratio associated with vintage $v$, which evolves as stated before. Since we do not have any disembodied technical change ex post by assumption, the capital-output ratio does not change once a vintage has been installed. $Q_{t}^{f}$ is the user price of a unit of fuel $\mathrm{f}$ used at time t. The price of fuels does not depend on the vintage $\mathrm{v}$ for which it is used. Hence, for all v, $Q$ only depends on t. $\varphi_{v}^{f}$ is the corresponding fuel-output ratio. $Y_{v}^{f}$ is the total capacity of vintage $v$ at its time of installation. That amount will decrease due to depreciation, as given by the term $e^{-\delta \cdot(t-v)} \cdot X_{v, t}^{f}$ is the amount of capacity of vintage $v$ that is actually used at timet.

In order to calculate the variance of the present value of total cost as given by (5), it should be noted that for constant expected growth rates for prices and capital and fuel coefficients, equation (5) can be approximated by:

$$
\begin{aligned}
P V \approx & \sum_{f} \sum_{t=1}^{\theta} e^{-\rho \cdot t} \cdot \sum_{v=1}^{t} P_{0}^{f} \cdot e^{\hat{p}^{f} \cdot v} \cdot\left(1+S_{1, v}^{f}\right) \cdot \kappa_{0}^{f} \cdot e^{\hat{\kappa}^{f} \cdot v} \cdot\left(1+S_{2, v}^{f}\right) \cdot\left(r_{0}+\delta+S_{3, v}^{f}\right) \cdot Y_{v}^{f} \cdot e^{-\delta \cdot(t-v)}+ \\
& \sum_{f} \sum_{t=1}^{\theta} e^{-\rho \cdot t} \cdot \sum_{v=1}^{t} Q_{0}^{f} \cdot e^{\hat{q}^{f} t} \cdot \varphi_{0}^{f} \cdot e^{\varphi^{f} \cdot v} \cdot\left(1+S_{4, v}^{f}\right) \cdot\left(1+S_{5, t}^{f}\right) \cdot X_{v, t}^{f}
\end{aligned}
$$

\footnotetext{
5 Note that a change in investment prices then affects only the marginal vintage in a technology family, as opposed to changing fuel prices that would affect all vintages in a technology family at the same time. So valuation at historic cost-prices introduces a qualitative difference between capital and fuel costs that would vanish if capital would be valued at replacement costs. Of course, there would still be the qualitative difference arising from capital costs being associated with capacity installed and fuel costs with capacity used.
} 
where $S_{1, v}^{f}=\sum_{j=1}^{v} \varepsilon_{j}^{\hat{P}, f}, S_{2, v}^{f}=\sum_{j=1}^{v} \varepsilon_{j}^{\hat{\kappa}, f}, S_{3, v}^{f}=\sum_{j=1}^{v} \varepsilon_{j}^{r}, S_{4, v}^{f}=\sum_{j=1}^{v} \varepsilon_{j}^{\hat{\varphi}, f}, S_{5, t}^{f}=\sum_{j=1}^{t} \varepsilon_{j}^{\hat{q}, f}$, and where $\varepsilon_{j}^{x, f}$ is the forecasting error for variable $\mathrm{x}$ associated with technology family $\mathrm{f}$ for time $\mathrm{j}$. Note the subscript $\mathrm{t}$ in $S_{5, t}^{f}$. The other sums of error terms all depend on $\mathrm{v}$. In equation (6), $\hat{p}^{f}$ and $\hat{q}^{f}$ are the expected growth rates of investment prices and fuel prices for technology family f. $\hat{\kappa}^{f}$ and $\hat{\varphi}^{f}$ are the rates of capital-and fuel-using technical change. ${ }^{6}$ All forecasting errors $\varepsilon_{j}^{x, f}$ are assumed to have zero expectation. ${ }^{7}$ After simplifying equation (6) it can be used to calculate the (approximated) expected forecasting error in the present value of total capital and fuel costs. The expectation of its squared value will then be the total variance of $\mathrm{PV}$ :

$\operatorname{var}(P V)=\sum_{f 1} \sum_{t 1=1}^{\theta} \sum_{k 1=1}^{5} \sum_{f 2} \sum_{t 2=1}^{\theta} \sum_{k 2=1}^{5} C_{k 1, t 1}^{f 1} \cdot C_{k 2, t 2}^{f 2} \cdot \sigma_{k 1, k 2}^{f 1, f 2} \cdot \min (t 1, t 2)$

where $\min (a, b)$ represents the minimum of $a$ and $b$, and where $k 1, k 2=1 . .5$ refers to the variables $\hat{p}, \hat{\kappa}, r, \hat{\varphi}, \hat{q}$ respectively, corresponding to technology families $\mathrm{f} 1$ and f2. $\sigma_{k 1, k 2}^{f 1, f 2}$ is the co-variance between variables $k 1$ and $k 2$ of technology families $\mathrm{f} 1$ and $\mathrm{f2}$. The terms involving $\mathrm{C}$ in (7) are defined in terms of those involving $\mathrm{S}$ associated with (6). For further details, see the appendix.

\subsection{The Objective Function}

As stated before, we assume that electricity producers want to minimise a weighted sum of the present value of total costs and its corresponding variance:

$\Phi=P V+\lambda \cdot \operatorname{var}(P V)$

\footnotetext{
${ }^{6} \mathrm{Negative}$ values of these rates imply capital- and fuel-saving technical change.

7 It should be noted that the forecasting errors in the interest rate are really independent of the technology family. However, for uniformity of notation we act as if they do depend on $\mathrm{f}$.
} 
where $\lambda$ is the relative contribution of the variance of the present value of total costs to the objective function. We will further assume that $\lambda$ is a non-negative constant.

Electricity producers are assumed to minimise (8) by choosing the optimum values of both initial vintage capacity $\Delta Y_{v}^{f}$ per technology family $f$ for all vintages to be installed during the planning period and a corresponding 'production plan' (i.e. $\Delta X_{v, t}^{f}$ ) for each vintage to be installed. $\Delta Y_{v}^{f}$ and $\Delta X_{v, t}^{f}$ are chosen conditional on the expected values and (co-)variances of the stochastic variables in this setting, i.e. investment and fuel price growth as well as the proportional rates of change of the capital- and fuel coefficients due to embodied technical change.

\subsection{Completing the model}

The full model now consists of the objective function (8) that needs to be minimised, subject to equations (7) and (6), where (6) is evaluated for all 'S-terms' equal to zero, in order to obtain the expected value of the present value of total costs. For each vintage in each technology family, we also have to take into consideration that actual output cannot be larger than capacity output. Hence, as additional constraints we have:

$$
\Delta X_{v, t}^{f} \leq e^{-\delta^{f} \cdot(t-v)} \cdot Y_{v}^{f}
$$

Finally, the aggregate demand constraint is given by:

$$
\sum_{v=1}^{t} \sum_{f} \Delta X_{v, t}^{f} \geq D_{t}
$$

where $D_{t}$ is the expected level of demand for time t. ${ }^{8}$

\footnotetext{
8 Again, uncertainty in demand can be covered by allowing for different scenarios, and making production plans scenario specific, whereas capacity investment plans are not. In addition to this,
} 


\section{Some model simulations}

\subsection{Introduction}

In order to illustrate the portfolio principles involved in the most transparent way possible, we want to avoid any effects that would arise from asymmetries in the characteristics of the technology families. In addition to this, three is the minimum number of technology families that could generate an interesting portfolio composition problem.

In the symmetric three technology family case, where the costs of investment and fuels, capital and fuel coefficients and initially installed capacity are all equal between families, we do indeed find a portfolio that is evenly spread across families. However, this only occurs if investors are risk averse, i.e. if $\lambda>0$. Otherwise, the distribution of investment across families is random, even though total investment is the same in all cases as it is implicitly defined by the total demand constraint. This randomness may seem somewhat odd at first. However, one should realize that in the absence of risk-aversion and under complete technology family symmetry, all technology families are perfect substitutes for each other, and so there are infinitely many optimum investment portfolios.

The fact that investment is distributed over technology families if $\lambda>0$, is caused by the convexity of the objective function that arises due to the inclusion of the variance term. As, roughly speaking, the variance of the total costs associated with each technology family depends quadratically on the size of the technology family, we will have lower total portfolio variance if capacity is distributed over all families rather than being concentrated in just one technology family. This, after all, is the way, in which diversification of risk in an optimum portfolio setting works. The evenness of the investment distribution arises due to the technology family symmetry assumptions we have used.

Given this basic set-up, we have conducted a sensitivity analysis regarding

the objective functions should be re-specified as a weighted sum over all individual demand scenarios, with their respective probabilities as weights. 
the responsiveness of investment behaviour towards changes in the variances of the stochastic variables associated with just one of the technology families, thus breaking the symmetry between technology families. These results are obtained for zero co-variances between expected price-growth and the various expected rates of technical change, both within and between technology families, even though the model has been specified for the non-zero co-variance case, again because this makes the results more transparent. But before discussing these results, it is useful to underline again that the valuation of investment at historic cost prices that we have implemented causes quite a qualitative difference between fuel price variance experiments and capital cost variance experiments. Higher fuel price variance at some moment in time affects all vintages within a technology family that are in existence at that time, whereas higher capital cost variance at some point in time only affects the vintages bought from that period on, just like more uncertainty about the productivity growth rate at some point in time does not affect the vintages installed before that period. In that sense capital cost variance and embodied technical change variance have some features in common with respect to the timing of investment.

\subsection{Sensitivity analysis}

\section{Experimental setting}

For the experiments we have used a forty year planning period. Moreover, all initial prices have a value equal to one, whereas the interest rate, the discount rate and the depreciation rate are all equal to five percent. Expected growth rates of prices are equal to one percent, and the expected rates of embodied factor saving technical change are all equal to one percent as well. The variance in expected capital cost growth is 0.002 , in expected fuel price growth it is 0.02 , and the variance in factor productivity growth and in the interest rate is equal to 0.01. Finally, total demand is equal to ten, and it grows by three percent per year. 
A reduction in fuel price variance

A zero variance in fuel price growth of TF ${ }^{9}$ (while leaving the other variances unchanged) brings investment in that technology family forward in time at the expense of investment in the other two technology families ${ }^{10}$. This is illustrated in Figure 1 below, that shows the percentage deviations of netinvestment relative to the base run. This finding is in line with the standard result known from OPT and real options theory, i.e. we also find a negative relationship between uncertainty and investment in this case. With higher uncertainty associated with investment in some technology family, investors will reduce investment in that family, since the risk-adjusted returns fall, which is the typical portfolio result. In real options theory terms, the value of waiting and postponing investment in that technology family is reduced if uncertainty decreases.

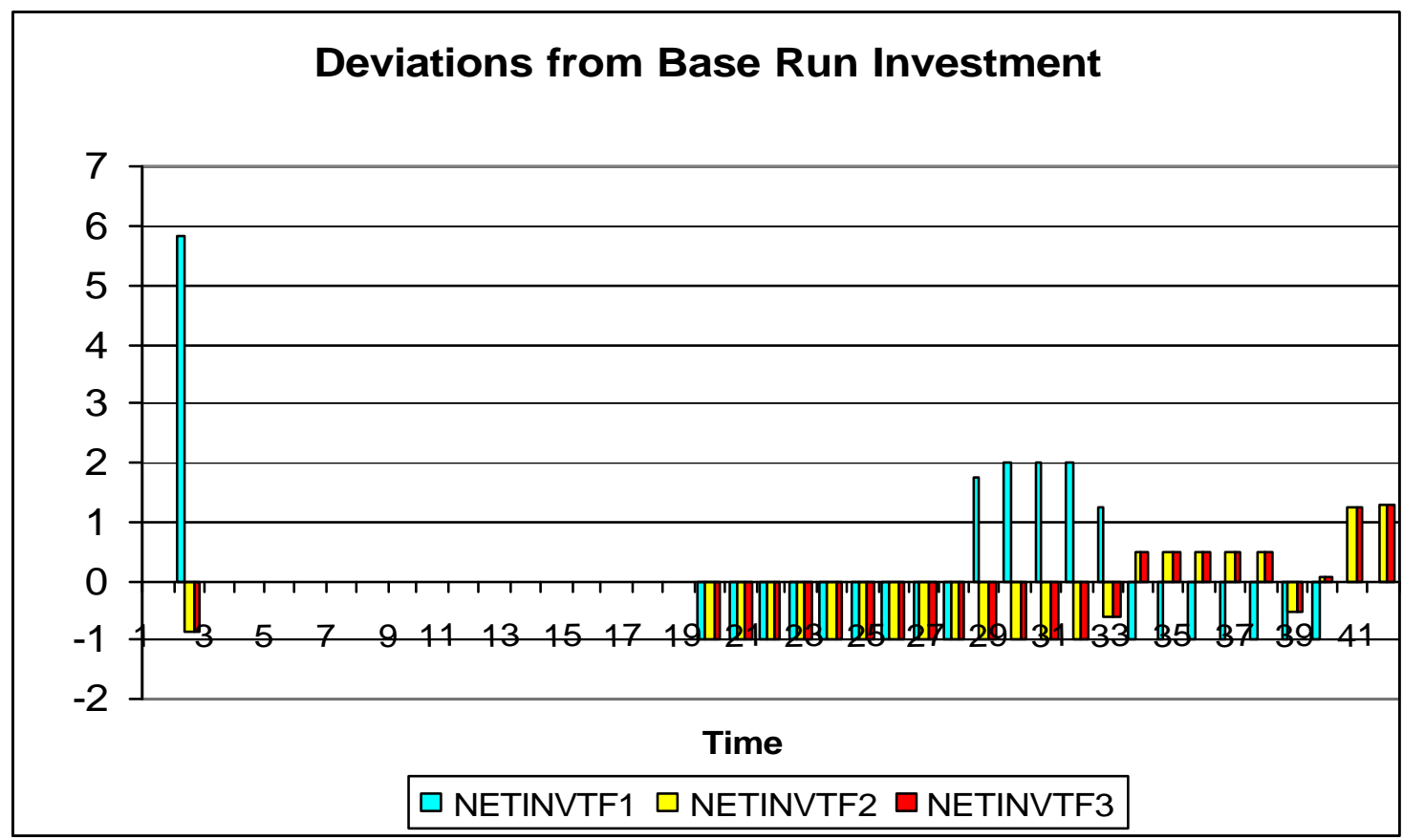

Figure 1: Deviations of net investment for zero fuel price growth variance in TF 1

In addition to this, it should be noted that the percentage increase in net investment in TF1 relative to the base run is larger than the sum of the

\footnotetext{
9 TFi is short for 'technology family i'.

10 Their overall share is lower, but the distribution among the two unchanged technologies remains the same, because the other two families are still symmetric but imperfect substitutes from a risk diversification point of view.
} 
percentage reductions in net investment in TF 2 and TF3. As the first vintage contributes more often to fuel costs than vintages that are installed at later moments in time, a reduction in the uncertainty surrounding the growth in fuel prices will have a larger effect if investment in the first year of the planning period in particular increases. This is indeed what happens. In general, however, we can conclude that the investment portfolio is reshuffled over both the family and the 'quality' dimension. In this particular case, the 'quality' of the aggregate capital stock falls due to the fact that aggregate investment is brought forward in time.

A reduction in investment price growth variance

For the experiment with zero variance in the rate of growth of investment prices we find a very small reduction in net investment in the first technology family in the beginning of the planning period, which is offset by higher investment later on (see Figure 2).

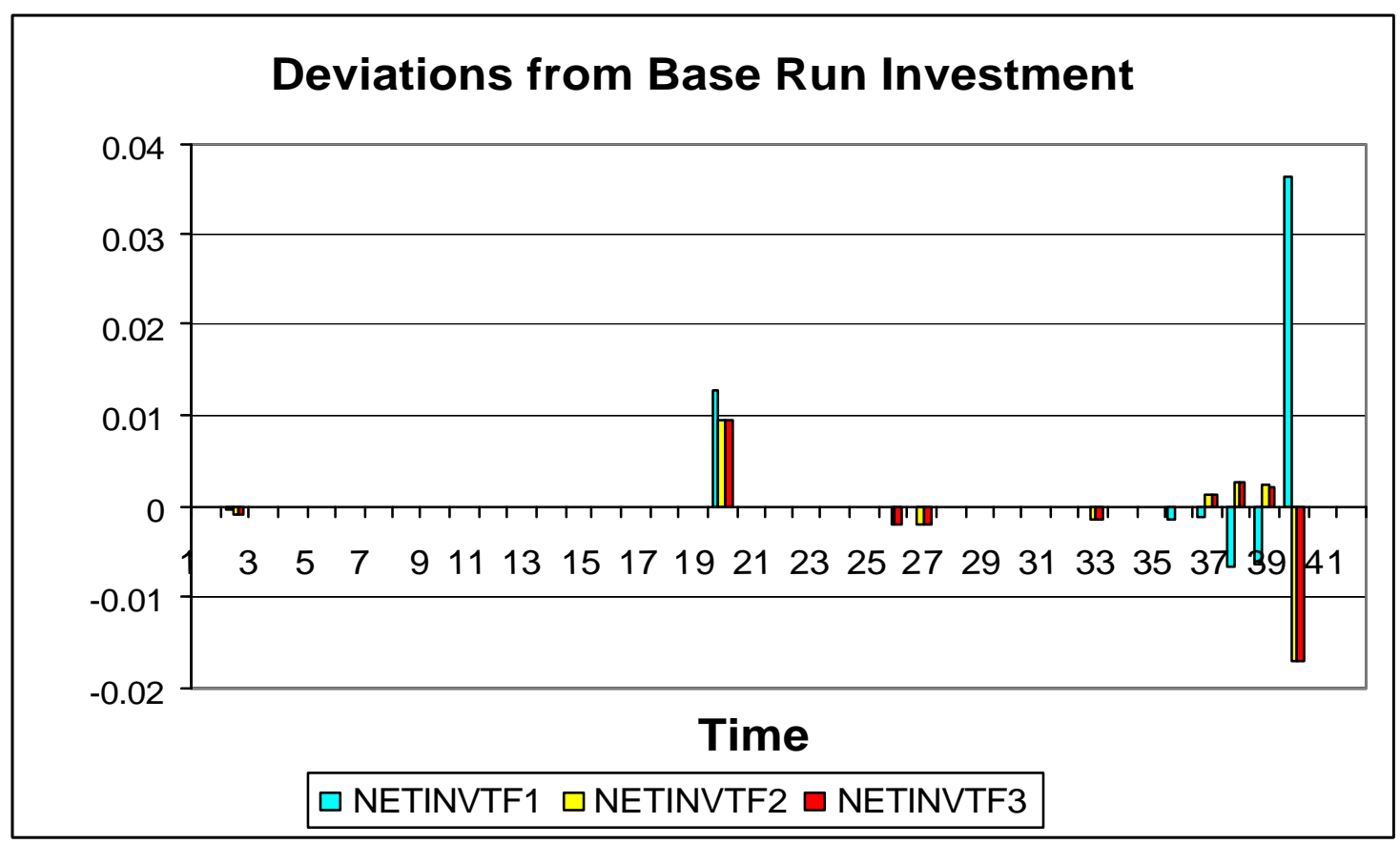

Figure 2: Deviations of net investment zero investment price growth in TF 1

The limited size of the effect is in part due to the fact that total capital costs are far less important an item in our set-up than fuel costs. Because of the 
relatively low contribution of capital costs to total costs, nothing much happens to current investment if the uncertainty regarding capital costs decreases. However, rather than an increase in aggregate investment levels, we find a decrease, al beit a small one, relative to the base-run, and a fairly high increase in investment in the middle of the planning period. At first sight, this seems odd. However, as stated above, changes in the (uncertainty surrounding the) investment price will only affect the latest vintage, while changes in fuel prices influence production costs on all existing vintages. Therefore, in the face of lower uncertainty about investment price growth, it pays to postpone investment as producers become more certain about future prices.

A reduction in the variance of embodied capital saving technical change

In this experiment, the results of less uncertain capital-saving technical change are again relatively insignificant in size, both because capital costs as such are far less important than fuel costs, and because the effect builds up over time, since technical change is a cumulative process that will now generate more certain outcomes. This is immediately apparent from Figure 3, where the investment shares become increasingly biased in favor of TF1 (the economic lifetime of equipment is about t wenty years, so the investment spikes in the middle of the planning period and at the end of the planning period are replacement effects, as well as echo-effects).

Even though the effects are numerically relatively insignificant as explained above, qualitatively they are very different from ordinary OPT results. We see that investment is postponed in this case, rather than being brought forward in time. The reason is that less uncertainty in technical change affects vintages to be installed far in the future to a much larger extent than vintages that will have had relatively little time to accumulate more certain technical change. In order to benefit from more certain technical change, postponing investment seems to be the logical thing to do, and this is indeed what we observe, even though investment is not that risky any more in terms of the volatility of returns. Our also contrast with those of Real Option Theory, that would predict that less uncertainty lowers the option value of waiting, and hence 
that investment would have to take place sooner rather than later. Finally, it should be noted that the OPT risk-diversification effect still works as expected, as net investment in TF 1 falls less than net investment in the dher technology families, thus effectively raising the portfolio-share of TF 1 in first period investment.

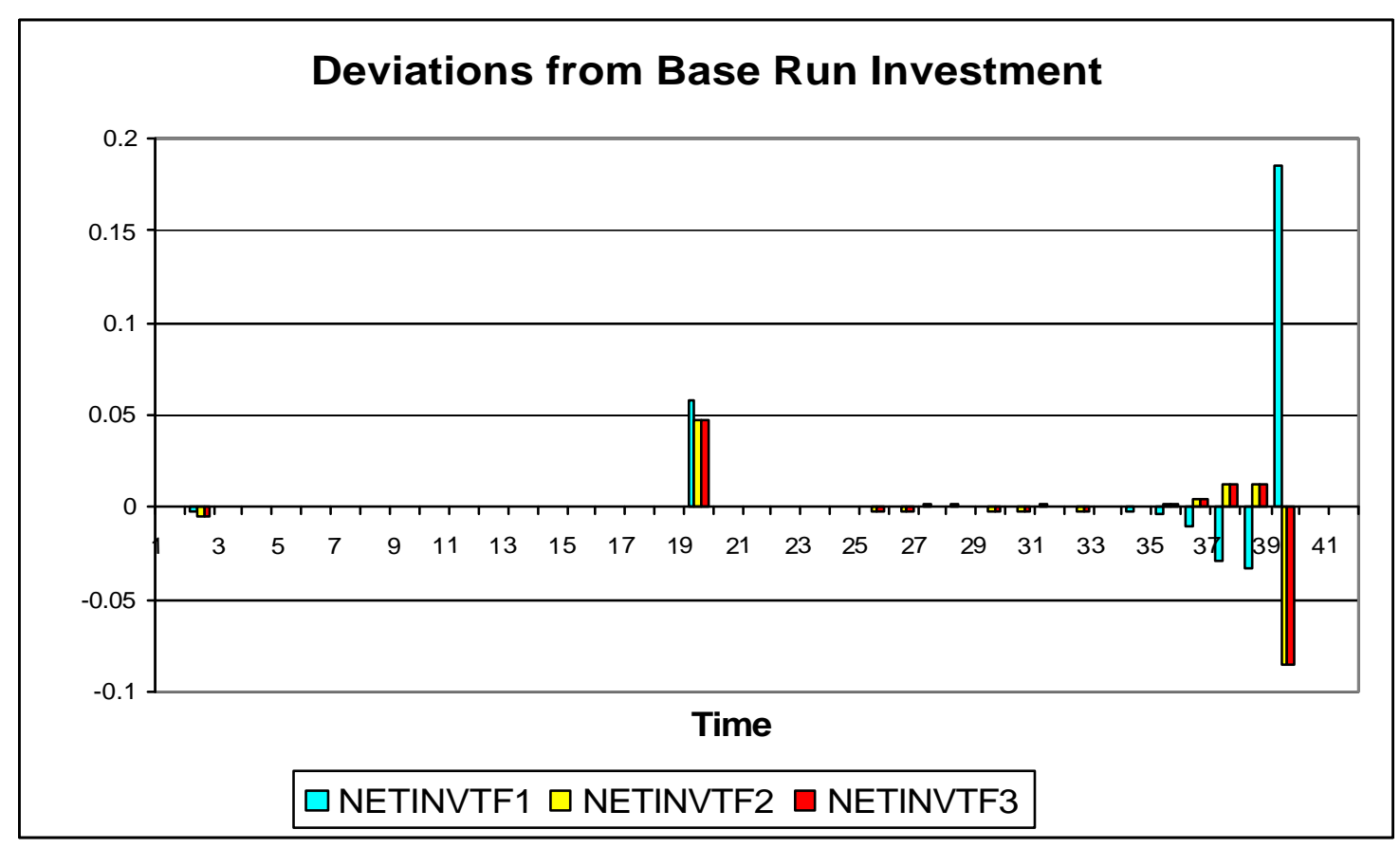

Figure 3: Deviations of net investment for zero variance in capital-saving technical change TF 1

A reduction in the variance of embodied fuel saving technical change

In this experiment, the results from the low fuel price growth variance experiment are significantly reversed, as can be seen in Figure 4 for fuel-saving technical change. What seems surprising in this figure is that the deviation in net investment turns positive right after the negative deviation in the beginning and turns slightly negative towards the end, which is offset by higher investment in the other two technologies. The reason for that behavior is that fuel efficiency matters a lot more in terms of total costs. Therefore, net investment is higher than in the base run already in the second period because it immediately and significantly pays off to have some more "advanced" capacity. Indeed, the vintages installed early in the planning period will have a more lasting effect 
than the vintages installed later, for a given value of economic lifetime, not only because they themselves contribute directly to total costs more often than later vintages, but also indirectly through the vintages that will replace them later on. This pattern is not observed for lower variance in capital-saving technical change, since in this case the opportunity costs of waiting are a lot lower than with lower fuel price growth variance. Note from Figure 4 that producers do indeed wait longer for the more certain benefits of technical change to occur, and then invest more than in the base run. From time 17 in the planning period, the balance in net investment does not only change in favor of TF 1 , but total netinvestment increases, making up for lower (even zero) subsequent net investment into TF 1 (and higher net investment into TF 2 and TF 3), as we can see that the drop relative to the base run is equal to 100 percent towards the end of the planning period.

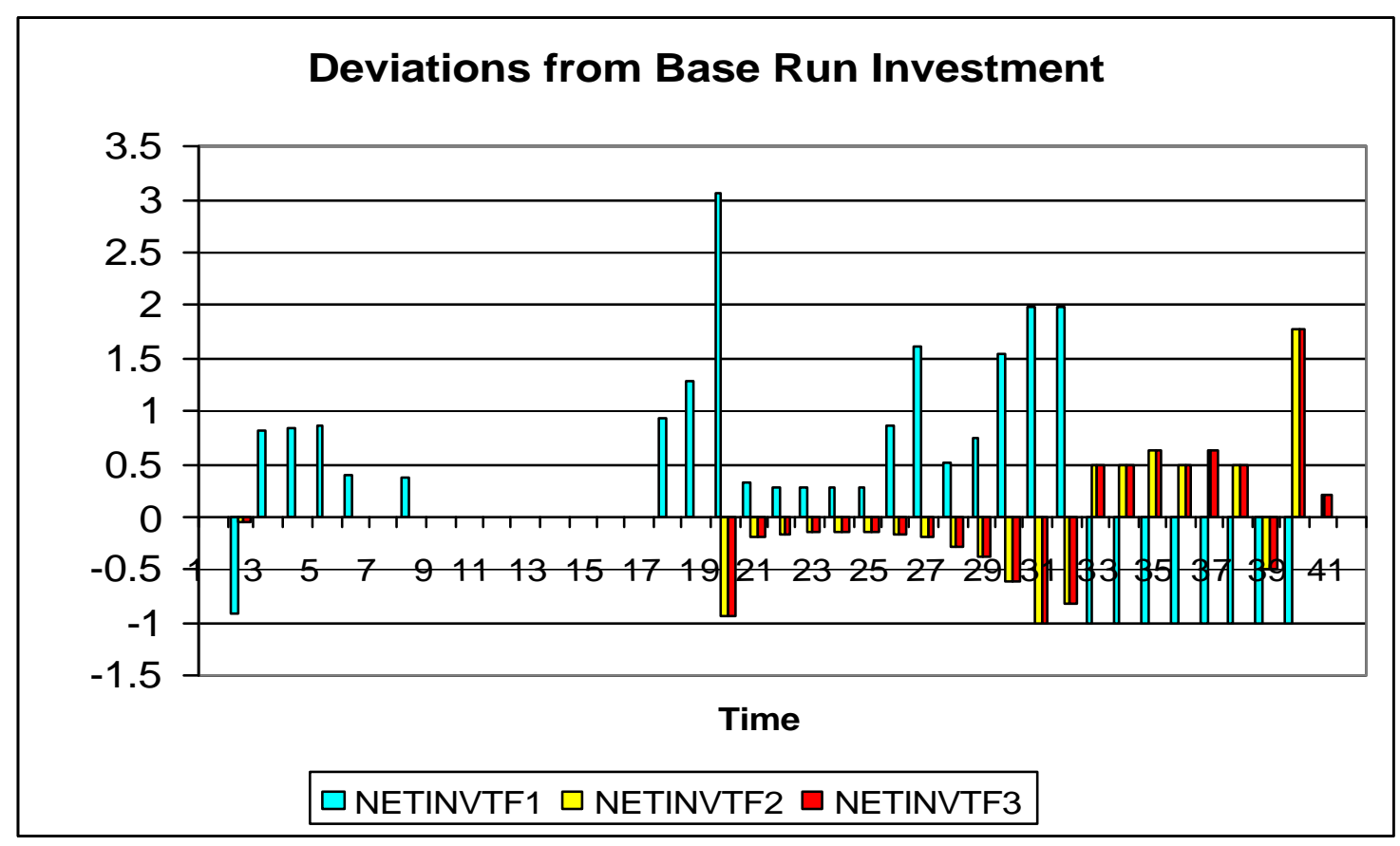

Figure 4: Deviations of net investment for zero variance in fuel-saving technical change of TF 1

\subsection{An asymmetric case}

Now that we have collected some qualitative theoretical results, namely that price uncertainty and investment are negatively related, as would be 
expected, and that the relation between technological uncertainty and investment is negative, which is at odds with standard portfolio and real options theory, but is completely rational in our model, we can turn to a more interesting case, where technologies have defining characteristics as in the real world.

\begin{tabular}{|c|c|c|c|}
\hline Parameter & TF1 & TF2 & TF3 \\
\hline$\kappa_{0}$ & 1.5 & 1.3 & 2 \\
\hline$\varphi_{0}$ & 2 & 1.5 & 2 \\
\hline$p_{0}$ & 1.5 & 1 & 0.5 \\
\hline$q_{0}$ & 1 & 1.5 & 0.002 \\
\hline$\hat{p}$ & 0.002 & 0.002 & 0.05 \\
\hline$\hat{q}$ & 0.05 & 0.05 & 0.001 \\
\hline$\sigma_{\hat{p}}^{2}$ & 0.001 & 0.001 & 0.01 \\
\hline$\sigma_{\hat{q}}^{2}$ & 0.01 & 0.015 & -0.00015 \\
\hline$\hat{\kappa}$ & -0.0005 & -0.0001 & -0.00015 \\
\hline$\hat{\varphi}$ & -0.0005 & -0.0001 & 0.02 \\
\hline$\sigma_{\hat{\kappa}}^{2}$ & 0.01 & 0.015 & 0.02 \\
\hline$\sigma_{\hat{\varphi}}^{2}$ & 0.02 & 0.025 & \\
\hline & & & \\
\hline & & & \\
\hline & & & \\
\hline
\end{tabular}

Table 1: Parameter values

As can be seen from Table 1 that presents the parameter values we have used in the asymmetric case, technology families 1 and 2 are relatively similar. The main difference between them is that the second technology family one uses more expensive fuels, but with a fuel price variance that is less than with technol ogy family 1 . The third technology family is very different from the others in that it has low capital productivity, high unit capital costs, but low fuel prices and a relatively strong rate of capital-saving technical change, while fuel-saving 
technical change is very low, since it is supposed to represent a "renewablesbased" technology, which will therefore use only very small amounts of fuels. Moreover, for this technology family technological expectations are not only positive but relatively certain, given the small variances in the growth rates of the technical coefficients. The technologies can ther efore be roughly characterised as follows. Technologies 1 and 2 are established technologies with limited scope for productivity improvements, possibly representing fossil-fuel-based conversion methods, such as coal (high capital costs, low fuel costs as with TF 1 ) and gas (high fuel costs, low capital costs as with TF2). However, the variance of the growth in fuel costs in technology family 2 is considerably higher than that in technology family 1 , which is comparable to gas and coal again. The third technology family is expensive in terms of capital costs, does not cost much in terms of fuels, and has plenty of scope for technological improvements and may thus represent a promising, yet underdeveloped technique based on a renewable resource.

Not surprisingly, for the case of zero risk aversion, we find that investment is completely focused on technology family 3 . It has the most favourable prospects in terms of technological change and is cheap in terms of fuels. Therefore, all investment goes into technology family 3 in the beginning of the planning period, and afterwards there is only marginal investment making up for growth in demand and depreciation of the existing capital stock as can be seen in Figure 5.

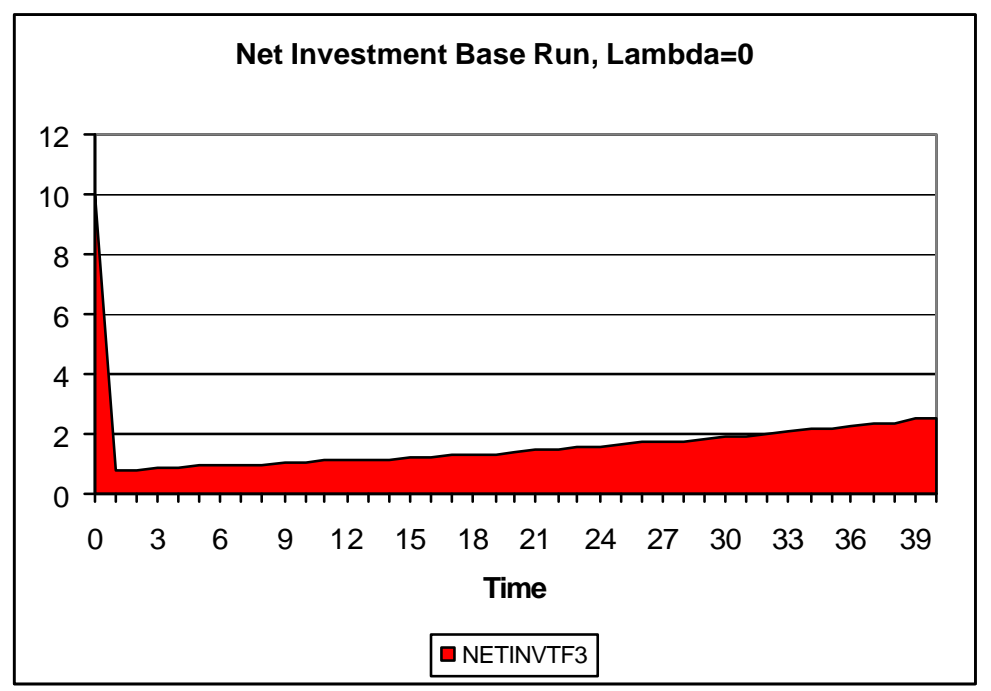

Figure 5: Base Run Investment without Risk Aversion 
However, from the description of the data above, we know that technology family 3 should look less attractive for investors, who are risk averse. The variance associated with capital-saving technol ogical change is high compared to the other two candidates and similar for fuel-saving technical progress. By increasing the weight of the variance in total cost (i.e. $\lambda$ ) in the objective function, we can investigate what happens to the investment portfolio as investors begin to care more about the risks involved in their investments.

Figures 6, 7 and 8 show that not only the spread across technology families increases as lambda rises, but that there are also strong effects with respect to the distribution of investment over time. In particular, we observe that most of the investment is brought forward in time, the more risk-averse investors grow. This is in line with our findings from the symmetric case. If investors dislike uncertainty a lot, there is no option value of waiting. They rather invest in the beginning, when they face relatively certain circumstances, than wait and being confronted with less favourable and unexpected outcomes over the course of the planning period. If they are really risk-averse, they would even go so far as to invest in capacity only at the beginning of the planning period, and have a huge degree of under-utilisation during most of the planning period (cf. Figure 8).

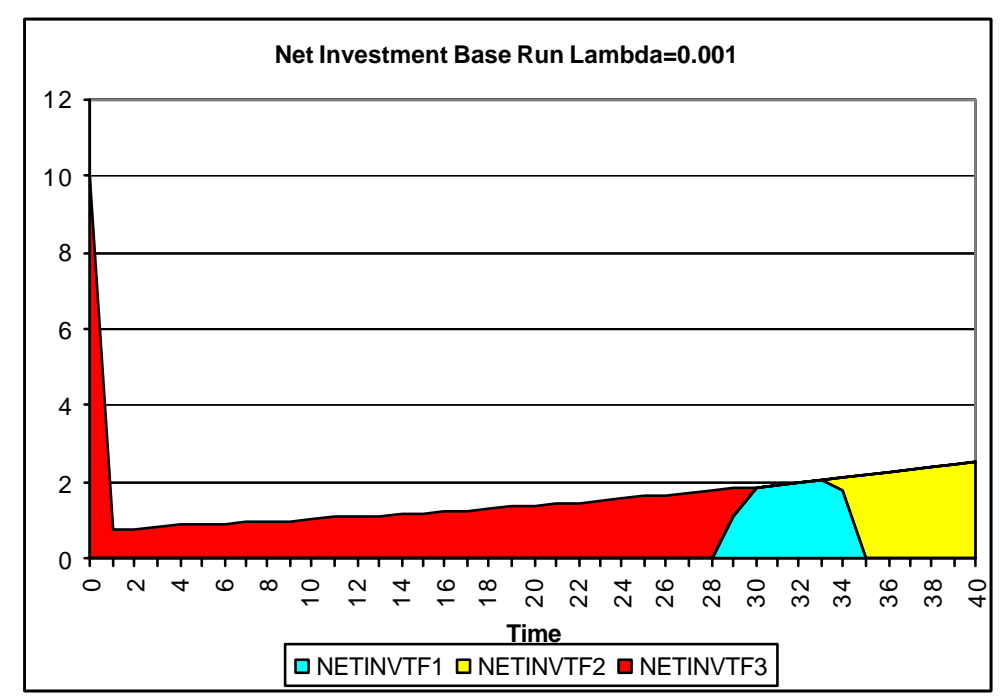

Figure 6: Base Run Investment with Slight Risk Aversion

In Figure 6 that corresponds with the low risk-aversion case, we see that technology family 1 is phased in at the beginning of period 29 and technology 
family 2 in period 34. This is a rational choice when looking back at the data. Technol ogy family 1 is less variable than technology family 2 in all respects and less variable than technology family 3 in most cases as well. Therefore, it can be used to effectively hedge against the risks that have to be borne in the case of technology family 3 . The fact that technology family 2 becomes an attractive investment opportunity after a considerable amount of time only also has to do with the fact that it has relatively high initial fuel costs, which constitute a large share in total costs.

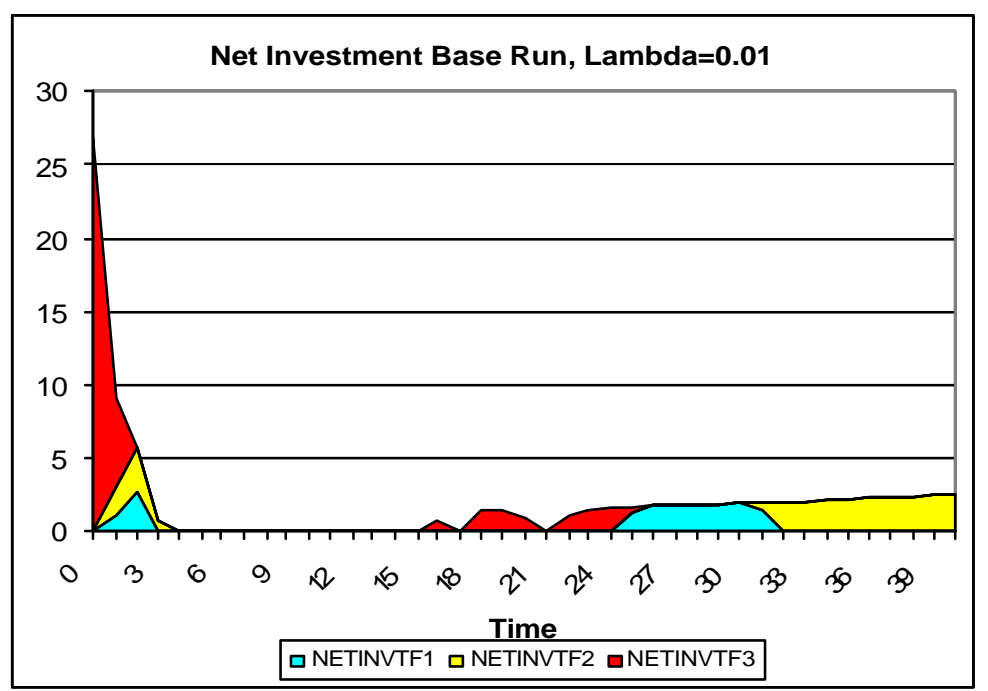

Figure 7: Base Run Investment with Moderate Risk Aversion

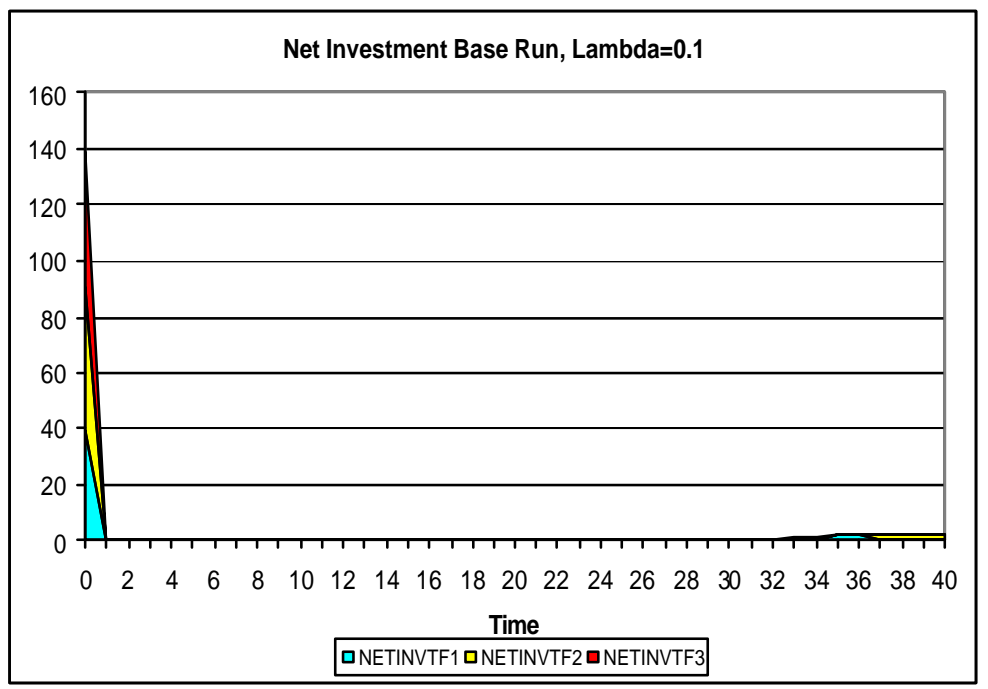

Figure 8: Base Run Investment with High Risk Aversion 
From the exercises above, we can conclude that portfolio theory seems to be a useful analytical tool to investigate investment choices in a context of uncertain embodied technical change. If we let one technology family be different from the others by having higher expected rates of technical change, but if at the same time there is considerable uncertainty that this technical change will indeed be realized (i.e. the variances of the rates of technical change are relatively higher), investors will start using this technology family only if they are not too risk averse. In addition we have seen that there are not only portfolio effects across technologies, but also across time, which in turn does not only depend on discount rates, but also on the degree of risk aversion.

\section{Summary and condusion}

In this paper we have illustrated the working of a vintage model of portfolio investment, in which two sources of uncertainty regarding future costs are present. We make a distinction between fixed and variable production costs. The fixed costs are associated with investment. They are only fixed ex post but variable ex ante, and need to be decided upon in the context of an investment portfolio problem that involves simultaneous investment in multiple basic production technologies, that we have called technology families. Each individual technology family is described using a vintage setting that allows for technological improvements to have cost-reducing effects through embodied technical change. However, realisation of these potential cost reductions requires investment. In order to accommodate these intertemporal cost reduction considerations in a "multiple choice" setting regarding production technologies that are developed and used in uncertain circumstances, we have defined an intertemporal, (cost) variance-adjusted, minimum cost function that borrows elements from financial optimum portfolio theory.

The model incorporates two sources of uncertainty: that about user prices of inputs, and uncertainty about capital embodied productivity changes of these inputs. Through some simulation experiments with the model, we have shown that the reaction of the model to changes in technological uncertainty is 
qualitatively different from its reaction to changes in (fuel) price uncertainty ${ }^{11}$. A decrease in uncertainty favours current investment in the case of lower price uncertainty, but it favours future investment in the case of a reduction in technological uncertainty. In the case of an uncertainty reduction in the growth of fuel prices, current investment in other technologies will increase, enabling the postponement of investment in the technology family experiencing the uncertainty reduction, since the given demand constraint must still be met The reason for this seemingly "perverse" reaction is that a decrease in the variance of the rate of technical change provides an incentive to actually postpone investment. The latter enables one to reap the productivity benefits of the cumulative nature of technical change that is assumed to continue regardless of the rate of investment itself. By reducing the uncertainty surrounding the benefits of waiting, it becomes more attractive to wait. Reductions in the uncertainty surrounding the variable costs of operating a vintage (i.e. fuel costs in our case) show the effects we would expect a priori. We observe an increase in investment in the technology, which has become less expensive to operate and a decrease in other technologies. While this is in line with real options theory, we have already pointed out that technological uncertainty gives us the opposite result. However, there are also models using real options that have found a positive impact of uncertainty on investment.

Sarkar (2000) presents a real options model, in which the probability of investment occurring within a specific time interval, is positively affected by higher uncertainty. Pindyck (1992) also distinguishes between input cost uncertainty, for which he finds the traditional real options result confirmed, and technical uncertainty, which tends to increase investment, though not very significantly. However, Pindyck's (1993) technical or construction cost uncertainty is due to information that will be revealed only after the first investments have taken place, ${ }^{12}$ which is very different from our definition of

\footnotetext{
11 Remember that this is different for investment costs, since lower variance in the growth rate of those will only affect the latest vintage and therefore represent an incentive to (slightly) postpone investment as well.

12 As an example, Pindyck presents a case where an investment of $\$ 1$ is required at first, after which there is a probability of $50 \%$ that the project will be finished. However, there is also a $50 \%$ chance that another investment of $\$ 4$ will be necessary. The completed project will have a certain
} 
technological uncertainty. Our initially negative but later positive relationship between investment and the reduction of uncertainty, derives from the fact that the investor will be able to reap the benefits of technical change that will be going on regardless of people's individual investment actions. In that case waiting brings the bonus of accumulating more certain (and positively valued) embodied technical change.

Finally, in performing the simulation experiments we found that a change in the temporal distribution of investment generally also changes the technology family distribution of investment, and vice versa, because both the temporal dimension and the technology family dimension become interconnected through the vintage setting in a context of variance-adjusted intertemporal cost minimisation. 


\section{Appendix}

We can simplify equation (6) by noting that the sums of all the error terms should be relatively small in absolute terms. This holds a fortiori for terms containing products of those sums. We can now approximate (6) by assuming terms containing products of at least two sums of error terms to be equal to zero. In that case, the expected forecasting error of PV will be given by:

$$
\begin{aligned}
\varepsilon^{P V} \approx & \sum_{f} \sum_{t=1}^{\theta} e^{-\rho \cdot t} \cdot \sum_{v=1}^{t} P_{0}^{f} \cdot e^{\hat{p}^{f} \cdot v} \cdot \kappa_{0}^{f} \cdot e^{\hat{\kappa}^{f} \cdot v} \cdot Y_{v}^{f} \cdot e^{-\delta \cdot(t-v)} \cdot\left\{\left(r_{0}+\delta\right) \cdot\left(S_{1, v}^{f}+S_{2, v}^{f}\right)+S_{3, v}^{f}\right\}+ \\
& \sum_{f} \sum_{t=1}^{\theta} e^{-\rho \cdot t} \cdot \sum_{v=1}^{t} Q_{0}^{f} \cdot e^{\hat{q}^{f} \cdot t} \cdot \varphi_{0}^{f} \cdot e^{\hat{\phi}^{f} \cdot v} \cdot X_{v, t}^{f} \cdot\left\{S_{4, v}^{f}+S_{5, t}^{f}\right\}
\end{aligned}
$$

In order to get rid of the summation over $v$, it should first be noted that equation (A.1) can be written in a more condensed way as:

$$
\varepsilon^{P V}=\sum_{f} \sum_{t=1}^{\ominus} \sum_{v=1}^{t}\left(\sum_{k=1}^{4} A_{k, v, t}^{f} \cdot S_{k, v}^{f}+A_{5, v, t}^{f} \cdot S_{5, t}^{f}\right)
$$

with $\quad A_{1, v, t}^{f}=Y_{v}^{f} \cdot P_{0}^{f} \cdot \kappa_{0}^{f} \cdot e^{-\delta \cdot(t-v)-\rho \cdot t+\left(\hat{\kappa}^{f}+\hat{p}^{f}\right) \cdot v} \cdot\left(r_{0}+\delta\right)$

$$
\begin{aligned}
& A_{2, v, t}^{f}=Y_{v}^{f} \cdot P_{0}^{f} \cdot \kappa_{0}^{f} \cdot e^{-\delta \cdot(t-v)-\rho \cdot t+\left(\hat{\kappa}^{f}+\hat{p}^{f}\right) \cdot v} \cdot\left(r_{0}+\delta\right) \\
& A_{3, v, t}^{f}=Y_{v}^{f} \cdot P_{0}^{f} \cdot \kappa_{0}^{f} \cdot e^{-\delta \cdot(t-v)-\rho \cdot p \cdot t+\left(\hat{\kappa}^{f}+\hat{p}^{f}\right) \cdot v} \\
& A_{4, v, t}^{f}=X_{v, t}^{f} \cdot Q_{0}^{f} \cdot \varphi_{0}^{f} \cdot e^{-\rho \cdot t+\phi^{f} \cdot v+\hat{q}^{f} \cdot t} \\
& A_{5, v, t}^{f}=X_{v, t}^{f} \cdot Q_{0}^{f} \cdot \varphi_{0}^{f} \cdot e^{-\rho \cdot t+\hat{\varphi}^{f} \cdot v+\hat{q}^{f} \cdot t}
\end{aligned}
$$

Then, it immediately follows that equation (A.2) in turn can be rewritten as:

$$
\varepsilon^{P V}=\sum_{f} \sum_{t=1}^{\theta} \sum_{v=1}^{t}\left(\sum_{k=1}^{4} A_{k, v, t}^{f} \cdot S_{k, v}^{f}+A_{5, v, t}^{f} \cdot S_{5, t}^{f}\right)=\sum_{f} \sum_{t=1}^{\theta} \sum_{k=1}^{5} C_{k, t}^{f} \cdot S_{k, t}^{f}
$$

with $\left.\quad C_{k, t}^{f}\right|_{k=1 . .4}=\sum_{v=t}^{\ominus} A_{k, t, v}^{f},\left.\quad C_{k, t}^{f}\right|_{k=5}=\sum_{v=1}^{t} A_{5, v, t}^{f}$ 
Equation (A.3) defines the expected forecasting error in the present value of total capital and fuel costs over the entire planning period in terms of the individual error terms associated with the various stochastic variables in the model. It should be noted that the 'weighting-parameters' $C_{k, t}^{f}$ depend explicitly on the capacity choices and (ex ante) production plans that need to be formulated at the beginning of the planning period. The actual values that these choice variables will take will indeed depend on the forecasting errors of the stochastic variables if we would be using an objective function that depends not only on the expected value of the present value of the total capital and fuel costs, but also on its (expected) variance. This variance is calculated as the expectation of the square of the error-term given by (A.3):

$$
\begin{aligned}
\operatorname{var}(P V)=E\left(\left\{\varepsilon^{P V}\right\}^{2}\right) & =E\left(\sum_{f 1} \sum_{t=1}^{\theta} \sum_{k 1=1}^{5} C_{k 1, t 1}^{f 1} \cdot S_{k 1, t}^{f 1} \cdot \sum_{f 2} \sum_{t 2=1}^{\theta} \sum_{k 2=1}^{5} C_{k 2, t 2}^{f 2} \cdot S_{k 2, t 2}^{f 2}\right)= \\
& =E\left(\sum_{f 1} \sum_{t=1}^{\theta} \sum_{k=1}^{5} \sum_{f 2} \sum_{t 2=1}^{\theta} \sum_{k 2=1}^{5} C_{k 1, t 1}^{f 1} \cdot S_{k 1, t 1}^{f 1} \cdot C_{k 2, t 2}^{f 2} \cdot S_{k 2, t 2}^{f 2}\right)= \\
& =\sum_{f 1} \sum_{t=1}^{\theta} \sum_{k=1}^{5} \sum_{f 2} \sum_{t 2=1}^{\theta} \sum_{k 2=1}^{5} C_{k 1, t 1}^{f 1} \cdot C_{k 2, t 2}^{f 2} \cdot E\left(S_{k 1, t 1}^{f 1} \cdot S_{k 2, t 2}^{f 2}\right)
\end{aligned}
$$

The final step in calculating the variance of the present value of total capital and fuel costs is to define the co-variances between the different sums of error terms $S_{k, t}^{f}$. These obviously depend on the co-variances between the individual error terms regarding the forecasts of the rates of technical change, but also the rates of growth in the price index of investment and the prices of fuels, as well as changes in the interest rate.

With respect to these co-variances, we assume first that they are constant over time, and secondly that the forecasting errors are serially uncorrelated. Hence, defining $\sigma_{k 1, k 2}^{f 1,2}$ as the covariance between the contemporaneous error terms associated with variable $k 1$ of technology family $f 1$ and variable $k 2$ of technology family f2, we will have: 
$\operatorname{var}(P V)=\sum_{f 1} \sum_{t 1=1}^{\theta} \sum_{k 1=1}^{5} \sum_{f 2} \sum_{t 2=1}^{\theta} \sum_{k 2=1}^{5} C_{k 1, t 1}^{f 1} \cdot C_{k 2, t 2}^{f 2} \cdot \sigma_{k 1, k 2}^{f 1, f 2} \cdot \min (t 1, t 2)$

where $\min (a, b)$ represents the minimum of $a$ and $b$, and where $k 1, k 2=1 . .5$ refers to the variables $\hat{p}, \hat{\kappa}, r, \hat{\varphi}, \hat{q}$ respectively, corresponding to technol ogy families $\mathrm{f} 1$ and $\mathrm{f} 2$. The minimum function arises here since there can only be non-zero correlation between two sums of error terms over different periods of time to the degree that these periods of time are overlapping. That is to say that under our assumptions of zero non-contemporaneous correlation between error terms, two forecasts for the same variable for two different points in time in the future $t 1$ and $t 2$, can be correlated with each other only through their common 'history'. Hence, when both forecasts would be formulated at time zero and counting time from time zero, the time-length of their common history would be the minimum of $\mathrm{t} 1$ and $\mathrm{t} 2$. 


\section{References}

- A werbuch, S. and Berger, M., 2003, Applying Portfolio Theory to EU Electricity Planning and Policy-making, Working Paper EET/2003/03, International Energy Agency, Paris.

- Dixit, A. and Pindyck, R., 1994, Investment under Uncertainty, Princeton University Press, New J ersey.

- Gregory, R.G. and J ames, D.W., 1973, Do New Factories Embody Best Practice Technology? The Economic J ournal, vol. 83, no. 332, pp. 1133-1155.

- Madlener, R., Kumbaroglu, G., Ediger, V.S., 2005, Modelling Technol ogy Adoption as an Irreversible Investment under Uncertainty: The Case of the Turkish Electricity Supply Industry, Energy Economics, vol. 27, no. 1, pp. 139163.

- Markowitz, Harry M., 1952, Portfolio Selection, J ournal of Finance, vol. 7, no. 1, pp. 77-91.

- Markowitz, Harry M., 1991, Foundations of Portfolio Theory, The J ournal of Finance, vol. 46, no. 2, pp. 469-477.

- Pindyck, R.S., 1991, I rreversibility, Uncertainty and Investment, J ournal of Economic Literature, vol. 29, no. 3, pp. 1110-1148.

- Pindyck, R.S., 1993, Investments of Uncertain Costs, J ournal of Financial Economics, vol. 34, no. 1, pp. 53-76.

- Robinson, J .V., 1962, Essays in the Theory of Economic Growth, London: Macmillan.

- Sarkar, S., 2000, On the Investment-Uncertainty Relationship in a Real Options Model, Economic J ournal, vol. 24, no. 2, pp. 219-225. 